\title{
What Should Be Done with Pernkopf's Anatomical Illustrations? A Commentary from the Medical University of Vienna
}

\author{
Herwig Czech, Ph.D.; Christiane Druml, LL.D.; Wolfgang J. Weninger M.D.; \\ and Markus Müller, M.D.
}

Thanks to a recent donation by Elsevier, the Medical University of Vienna now holds in its collections the known existing original paintings for Eduard Pernkopf's Atlas of Topographical and Applied Human Anatomy. The work is widely considered a pinnacle of the art of anatomical illustration. However, it is severely tainted by its historical origins. Pernkopf was a high-ranking National Socialist and co-responsible for the expulsion of hundreds of Jewish scientists and students from the university. Also, the Vienna Institute of Anatomy, which Pernkopf headed, received during the war the bodies of at least 1377 people executed by the regime, many for their political views or acts of resistance, including at least seven Jewish victims. Although it is impossible to individually identify the people used for the atlas, it is to be assumed that a considerable number of the paintings produced during and after the war are based on the bodies of these victims. Against this background, and out of respect for the victims, use of Pernkopf's atlas and its illustrations in medical teaching, training and practice should be - wherever possible without compromising medical outcomes - reduced to a minimum. Given the high variability of human anatomy, even the most detailed anatomical illustrations cannot replace teaching and training in the dissection room. As the experience at the Medical University of Vienna and elsewhere demonstrates, Pernkopf's atlas is far from irreplaceable. In keeping with the stipulations of the contract of donation, the Medical University of Vienna considers the Pernkopf originals primarily as historical artifacts, which will support the investigation, teaching and commemoration of this dark chapter of the history of medicine in Austria, out of a sense of responsibility towards the victims.

OPEN ACCESS
Eduard Pernkopf's career as an anatomist, his role as a Nazi activist and university official, and the creation of his atlas of anatomy are part of the difficult historical legacy of the Medical University of Vienna (Vienna University's Faculty of Medicine became an independent university in 2004). It is in this context that the donation in December 2019 of the 417 known extant original paintings (and 388 proofs) from Elsevier to the Josephinum (home of the Medical University's extensive historical collections) is significant, as an opportunity to shed a clearer light on the historical facts and their implications for today, and to acknowledge and commemorate the victims of unethical medical research. ${ }^{1}$

Eduard Pernkopf started working on a richly illustrated textbook in the 1930s and published a first volume in 1937. In the following years it was extended into a fourvolume-atlas (in seven books), appreciated for its highly detailed, well-arranged drawings allowing the reader to quickly and comprehensively study the complex topology of all body regions. Thanks to a smooth and highly successful collaboration between physicians doing dissection and skilled illustrators, even small anatomic details were clearly carved out, painted and meticulously labeled (Pernkopf 1937-1960).

A two-volume edition of the paintings without the accompanying, lengthy text, and prepared posthumously by one of Pernkopf's assistants, paved the way to an international success story with editions in German, English and several other languages (Pernkopf 19631964a), (Pernkopf 1963-1964b). ${ }^{2}$ Up to the 1990s many of these drawings were not only published in Pernkopf's atlas, but were also used in a number of other anatomy books and atlases, such as the Sobotta Atlas of Anatomy or Clemente's Anatomy. ${ }^{3}$

Beginning in the mid-1980s, the problematic context of the paintings' partial origins in Nazi Vienna increasingly came to light (Weissmann 1985), (Williams 1986), 
(Williams 1988). Against this background, the publisher Urban \& Schwarzenberg (later acquired by Elsevier) decided to stop printing or licensing of the atlas or its illustrations in 1994. In 1998, a commission appointed by the University of Vienna delivered a comprehensive report, documenting in detail how the Vienna anatomical institute had received, apart from thousands of corpses from public hospitals, at least 1377 corpses (including seven Jewish victims) of people who had been executed by the regime. The commission came to the conclusion that in all likelihood, a considerable number of the illustrations in the Pernkopf atlas were produced using victims of the Nazi judicial system (Akademischer Senat der Univ. Wien 1998), (Angetter 2000), (Hubenstorf, 2000).

The contract of donation with Elsevier stipulates that the Medical University takes responsibility for appropriate archiving and conservation, cataloging and digitization, as well as for providing access to the illustrations for historical and related research, provided an appropriate contextualization of the sensitive subject-matter can be guaranteed. In this context, Elsevier also granted the publishing rights to the Medical University under certain conditions: Elsevier has to approve if more than three illustrations are to be used within the same work, and commercial use in anatomical textbooks and comparable works is excluded (Czech et al. 2021). In a previous paper on the donation of the paintings, three of us have expressed our expectation that the medical relevance of the paintings will continue to fade, and that in line with the spirit and letter of the contract of donation, the "primary context in which these illustrations will appear is expected to be the history and ethics of anatomy and related topics" (Czech et al. 2021). There was - and is - no intention on the part of the Medical University of Vienna to facilitate or promote the use of these illustrations for teaching anatomy or surgery.

The fundamental question is, given the serious ethical issues surrounding it, do we need the Pernkopf atlas, or the paintings produced for it, in medical teaching and training, or in clinical practice? Regarding general anatomical teaching, the answer is, no. At the Medical University of Vienna each year, almost 700 students of medicine and 100 students of dentistry are taught anatomy primarily in dissection classes. Groups of six carefully explore anatomic details, such as the stratification of body walls and the branching patterns of nerves and vessels via hands-on dissection, guided and supervised by fellow students and academics. The dissection classes follow carefully defined educational objectives and instructions and are supported by digital resources, which include region specific video material. To work out basic topology, systematics and terminology, students are free to choose and use their preferred textbooks, atlases and lexica. We are not aware that during the last decades, students would have felt compelled to consult Pernkopf's publication. The same is true for students, trainees and residents, who wish to immerse themselves deeper in anatomy, who are educated according to the same standards. As far as we know, the principles that are applied in Vienna guide anatomical teaching throughout the world, as long as the procurement of a sufficient number of bodies is possible. Although one might think at first glance that anatomic education would dramatically profit from comprehensively labeled, highly detailed anatomical drawings such as those presented in the Pernkopf atlas, this is only partially true. High detail graphic representations, especially of small nerves and vessels, can also be confusing and lure students into expecting to expose precisely the illustrated situation when dissecting an anatomic region or organ. This is problematic, because the morphology and arrangement or even the mere presence of superficial structures, and the appearance of internal organs and tissues vary considerably between individuals. Countless variations of the branching patterns and arrangements of nerves and vessels are possible. Since each single variation of an organ, muscle, fascia, nerve or vessel is combined with variations of nearby structures, myriads of different possibilities must be considered as perfectly normal and healthy - a variability that no anatomical atlas, however sophisticated, could ever fully capture. In Vienna, students and residents are therefore encouraged to study all of the approximately 120 bodies dissected by fellow students during the regular and advanced dissection classes.

The question is more complicated when it comes to surgery. Several authors have argued that Pernkopf's atlas is a valuable, even irreplaceable, resource in the preparation of specific operations (Yee, Coombs, et al. 2018), (Yee, Zubovic, et al. 2018), (Mackinnon 2020). If a surgeon considers consultation of the Pernkopf atlas (or its illustrations) necessary to improve the outcome for a specific patient, there is a compelling argument that the ethically correct action is to do so. This is also in line with Rabbi Joseph A. Polak's discussion of the issue from the standpoint of rabbinic law in the Vienna Protocol, which stipulates that users of the illustrations should be fully aware of the historical context and acknowledge the 
victims (Polak 2018). However, we share Rabbi Polak and Michael Grodin's reservation against overstretching the principle of "saving a life" as a justification for continued use of the atlas (Polak and Grodin 2018).

Again taking the Medical University of Vienna as an example, what we have said about anatomical teaching on all levels also applies to highly specialized surgical training. Each year, approximately 3500 surgeons, dental surgeons and practitioners from related fields from all over the world (including the US) take postgraduate courses at the Division of Anatomy, most of them geared towards learning or improving specific operation techniques. It is also possible to simulate full operations, or difficult parts of interventions on non-embalmed body donors immediately before performing surgery on a patient. Together with becoming familiar with the most important variations by consulting suitable resources, this optimally prepares surgeons for their tasks. In our opinion, these options substantially reduce any value Pernkopf's atlas might have for trainees and experienced surgeons. We believe that no anatomical illustration,
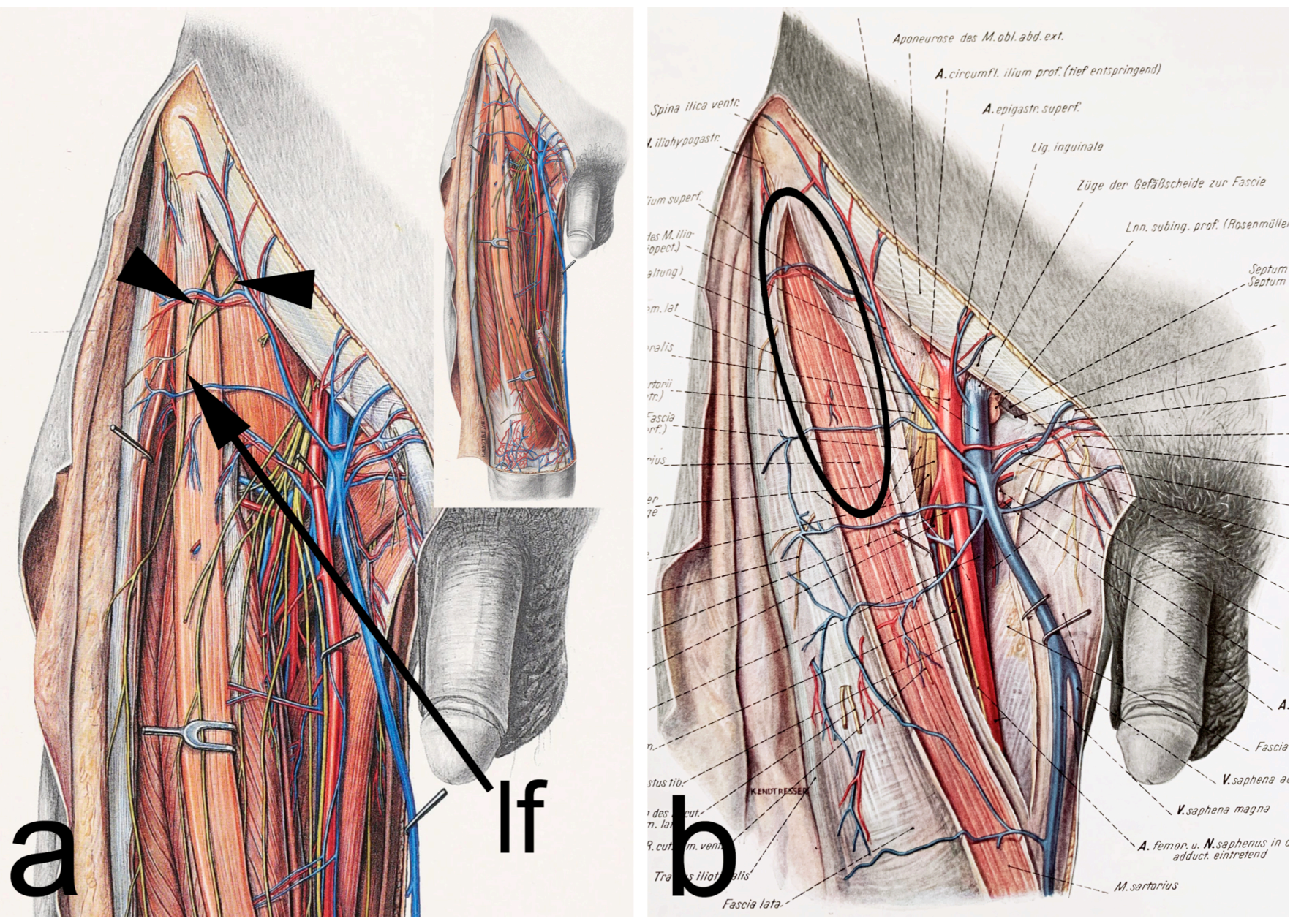

Figure 1: Anatomy of the proximal anterior upper leg as illustrated in Pernkopf's atlas. Figure a: Upper part of the illustration selected by (Yee, Coombs, et al. 2018) (first published in 1941 as figure 188 in volume II of Pernkopf's original German edition). The inlay shows the complete illustration (with an SS symbol in the signature). The fascia lata and the fasciae of the muscles are removed. Two nerves of equal diameter (arrowheads) exit the pelvis and join anterior to the sartorius muscle to form the lateral femoral cutaneous nerve (If). This situation is not to be expected in the average individual - it is a very rare variation. Note how the lateral femoral cutaneous nerve continues as an essentially single nerve stem that gives rise to several small branches. Figure $\mathbf{b}$ in the atlas precedes $\mathbf{a}$. In Figure b, the fasciae covering the muscles are still intact except for the slit anterior fascial sheet of the sartorius muscle. Note the missing stem of the lateral femoral cutaneous nerve, which according to a and the branches plotted there would be expected in the marked area. (Since in this case the original paintings are missing, the scans shown here were made using the Josephinum's collection of proofs or test prints as a substitute; image credit: Medical University of Vienna, MUW-AD-3250-5-336-11-Seite-1 and MUW-AD-3250-5-337-1. 
however detailed, could improve - much less replace this training, which is made possible by approximately 1000 body donations per year. Regarding individual surgeons, the anecdotal evidence we have from colleagues in various surgical specializations also does not indicate a need to use Pernkopf's work. According to (Yee, Coombs, et al. 2018), 87 percent of the nerve surgeons who answered a survey were not using Pernkopf's atlas (with 41 percent not even knowing of its existence). These numbers are hardly a compelling argument that Pernkopf's work is irreplaceable in surgery.

In principle, high quality illustrations are an essential resource and an important piece for planning and doing surgery. However, we would like to caution against overly relying on a single, authoritative source such as the Pernkopf atlas and its illustrations; we should keep in mind that if a given operation proves difficult, the cause might very well be an atypical situs, in which case consultation of an illustration depicting the norm variant might even be counterproductive.

It should also be noted that Pernkopf's work is not unassailable. Errors and inaccuracies have been pointed out in the literature, e.g. (Newell 1980). Interestingly, the image used by (Yee, Coombs, et al. 2018) to illustrate the superiority of Pernkopf's atlas can also serve as an example. It displays the lateral femoral cutaneous nerve in a rare variation rather than the norm, and from a related illustration the stem of the same nerve seems to be missing (Figure 1).

In cases where using the atlas is indeed the only or best hope to improve or save the life of a patient, nobody will reasonably object to such an ultima ratio. But, as argued above, we are convinced that such situations can be significantly reduced by relying on alternative resources and training methods. And there is certainly no necessity to use Pernkopf's atlas in basic medical education and training. Therefore, given the tainted context of Pernkopf's research, it should be replaced by other resources wherever possible. We also need to take into account the danger that a continued use of the atlas even if its historical roots are made transparent and the victims are properly recognized - may have the unwanted effect of creating the impression that great scientific results can be achieved by pushing aside ethical norms. Anatomists, surgeons and medical educators everywhere should strive to make this work obsolete, wherever possible.
We think this is feasible, at least regarding the direct use of Pernkopf's books and the illustrations that were produced for it. As mentioned above, the paintings have themselves served as models for other paintings, sometimes leading to more or less exact copies, sometimes serving as an inspiration for a specific view or composition. It is important to recognize and disclose this diffusion of Pernkopf's research, because some of this knowledge is still circulating, and it remains connected to the unethical use of victims of the Nazi regime.

Regarding the existing copies of Pernkopf's atlas, Rector Müller and Professor Druml, on behalf of the Medical University of Vienna, have created a Note to the Users of Pernkopf's Atlas of Topographical and Applied Anatomy (published in this issue), in the hope that libraries (and other owners) around the world will insert it into the books in their possession.

The Pernkopf paintings are now part of history, and this will be underlined by the exhibition of items from the collection at the newly renovated Josephinum, planned to open in 2022. The Josephinum is a late-18th-century palais, built under emperor Joseph II as a militarysurgical academy, which has served since 1920 for the study of the history of medicine and as the home of the Medical University's extensive historical collections. The most important of these is a set of over one thousand anatomical wax models acquired by Joseph II from Northern Italy, and with this the history of anatomical modeling and illustration will be a central element of the new museum. At the same time, there will also be a strong focus on the history of medicine during National Socialism, from the expulsion and persecution of a large part of the members of the Vienna Medical School because of their Jewish origin or political background, to the University's contributions to race hygiene, unethical or outright criminal research, and mass murder. In this context, it will also be essential to acknowledge and commemorate the many victims whose bodies were delivered to the Institute of Anatomy under Pernkopf's responsibility. The paintings of the Pernkopf collection will be exhibited in this context, illustrating both a culmination of the Viennese Anatomical School, and its darkest chapter. 
${ }^{1}$ The donation comprises 417 out of the first edition's original 925 illustrations (not counting $\mathrm{x}$-ray images and other photos). The considerable losses are partially compensated by the 388 proofs. For a more detailed description of the collection and the losses, see (Czech et al. 2021).

${ }^{2}$ For a complete list of editions, see (Czech et al. 2021).

${ }^{3}$ For Clemente's Anatomy, originals from the Pernkopf atlas were used; for the Sobotta Atlas of Anatomy, one of Pernkopf's artists, Erich Lepier, was commissioned to copy a number of the originals. In the forthcoming 25th (German) edition, this link to Pernkopf will be made transparent for the first time [personal information from Sabine Hildebrandt; on Clemente's Anatomy, see https://mvccanatomy.org/the-pernkopf-project-2/, accessed 12 July 2021].

\section{Acknowledgements}

Sabine Hildebrandt (Boston Children's Hospital, Harvard Medical School) was instrumental in making the transfer of the collection to Vienna possible and gave helpful feedback on a draft of this article. David Williams, who played a central role in bringing to light Eduard Pernkopf's tainted history, donated his personal papers, books and art works pertaining to Pernkopf - including an original painting by Franz Batke - to the Medical University of Vienna, complementing the collections on the subject, for which we are very grateful. Last but not least, the authors wish to thank Oonagh Hayes for her help with editing the final text.

\section{References}

Akademischer Senat der Univ. Wien, ed. 1998. Untersuchungen zur anatomischen Wissenschaft in Wien 1938-1945. Senatsprojekt der Universität Wien. Wien.

Angetter, Daniela. 2000. "Anatomical science at University of Vienna 1938-45." The Lancet 355 (9213):1454-1457. (Republished in this issue of the Journal of Biocommunication) https://doi.org/10.5210/jbc.v45i1.11741
Czech, Herwig, Christiane Druml, Markus Müller, Max Voegler, Andrea Beilmann, and Nick Fowler. 2021. "The Medical University of Vienna and the legacy of Pernkopf's anatomical atlas: Elsevier's donation of the original drawings to the Josephinum." Annals of Anatomy - Anatomischer Anzeiger 237:1-8. doi: https://doi.org/10.1016/j.aanat.2021.151693.

Hubenstorf, Michael. 2000. "Anatomical science in Vienna, 1938-45." The Lancet 355 (9213):1385-1386.

Mackinnon, Susan E. 2020. "When medical information comes from Nazi atrocities." British Medical Journal 368:17075. https://www.bmj.com/content/368/bmj.17075.

Newell, Frank W. 1980. "Eduard Pernkopf Atlas of Topographical and Applied Human Anatomy, Volume I [review]." American Journal of Ophthalmology 90:754.

Pernkopf, Eduard. 1937-1960. Topographische Anatomie des Menschen, Band 1 bis 4. Berlin/Wien/München: Urban und Schwarzenberg.

Pernkopf, Eduard. 1963-1964a. Atlas der topographischen und angewandten Anatomie des Menschen in zwei Bänden, herausgegeben von Helmut Ferner. Erster Band: Kopf und Hals. Zweiter Band: Brust, Bauch und Extremitäten. München/Berlin: Urban \& Schwarzenberg.

Pernkopf, Eduard. 1963-1964b. Atlas of topographical and applied human anatomy. Volume 1: Head and neck, 1963. Volume 2: Thorax, abdomen and extremities, 1964. Philadelphia and London: W.B. Saunders Co.

Polak, Rabbi Joseph A. 2018. "Vienna Protocol for when Jewish or Possibly-Jewish Human Remains are Discovered." In Medical Ethics in the 70 Years after the Nuremberg Code, 1947 to the Present. International Conference at the Medical University of Vienna, 2nd and 3rd March 2017. Wiener klinische Wochenschrift 130 (Supplement 3), edited by Herwig Czech, Christiane Druml and Paul Weindling, S239-243. Wien: Springer.

Polak, Rabbi Joseph A., and Michael A. Grodin. 2018. "Letter: Nerve Surgeons' Assessment of the Role of Eduard Pernkopf's Atlas of Topographical and Applied Human Anatomy in Surgical Practice." Neurosurgery 83 (4):E188.

Weissmann, Gerald. 1985. "Springtime for Pernkopf." Hospital Practice (October 15):142-168. 
Williams, David J. 1986. "Eduard Pernkopf and the Pernkopf Painters." In Actes/Proceedings of the XXX. International congress of the History of Medicine Düsseldorf 1986, 524-533. Düsseldorf.

Williams, DJ. 1988. "The history of Eduard Pernkopf's Topographische Anatomie des Menschen." Journal of Biocommunication 15 (2):12.

Yee, Andrew, Demetrius M. Coombs, Sabine Hildebrandt, William E. Seidelman, J. Henk Coert, and Susan E. Mackinnon. 2018. "Nerve Surgeons' Assessment of the Role of Eduard Pernkopf 's Atlas of Topographical and Applied Human Anatomy in Surgical Practice." Neurosurgery 84 (2):491-498.

https://doi.org/10.1093/neuros/nyy159

Yee, Andrew, Ema Zubovic, Jennifer Yu, Shuddhadeb Ray, Sabine Hildebrandt, William E. Seidelman, Rabbi Joseph A. Polak, Michael A. Grodin, Henk Coert, Douglas Brown, Ira J. Kodner, and Susan E. Mackinnon. 2018. "Ethical considerations in the use of Pernkopf's Atlas of Anatomy: A surgical case study." Surgery 165 (5):860-867. doi: https://doi.org/10.1016/j.surg.2018.07.025.

\section{About the Authors}

Herwig Czech, M.A., Ph.D., is professor of history of medicine at the Medical University of Vienna, Department of Ethics, Collections and History of Medicine (Josephinum); he co-directs the research project "Brain research at institutes of the Kaiser Wilhelm Society in the context of National Socialist crimes," funded by the Max Planck Society. His main fields of research are medicine and biopolitics before, during and after National Socialism, with a special focus on the history of eugenics and racial hygiene, public health, psychiatry, pediatrics and neuropathology. Since January 2021, he is a member of the Lancet Commission on Medicine and the Holocaust.

Christiane Druml, LL.D., studied law at the University of Vienna. She holds the UNESCO Chair on Bioethics at the Medical University of Vienna and serves as Director of Ethics, Collections and History of Medicine at the Medical University of Vienna since 2016. Since the establishment of the Ludwig Boltzmann-Institute for Rare and Undiagnosed Diseases in 2016, she acts as Deputy Director and key researcher of the Bioethics
Research Group. In 2007, Druml was appointed as President of the Austrian National Bioethics Commission by the Austrian Federal Chancellor. She is a member of the Corona Task Force of the Federal Minister of Social Affairs, Health, Care and Consumer Protection of the Republic of Austria and serves furthermore in many international functions.

\section{Wolfgang J. Weninger, M.D.}

(http://www.wolfgangweninger.at/) graduated as MD in 1995 and started residency in Anatomy at the University of Vienna. 2000 he was invited to the NIMR (Crick Institute), London, where he and Tim Mohun patented a histologic imaging method. In 2002 he habilitated at the University of Vienna. In 2015 Weninger received an honorary Professorship from IMC-Krems, and in 2016 he was appointed head of the Division of Anatomy of the Medical University of Vienna and Scientific Director of BioImaging Austria. After becoming short listed for full Professorship in Anatomy at the Medical Universities Graz and Vienna, in 2018 he accepted the call to Vienna. Since 2020 he is speaker of the Medical Imaging Cluster. Weninger is engaged in pre- and postgraduate education in medicine, dentistry and physiotherapy and is member of curricular boards of four Universities. His research focus lies on clinically applied anatomy, developmental biology and multimodal imaging.

Markus Müller, M.D., is Professor of Internal Medicine and Clinical Pharmacology and serves as President of the Medical University of Vienna since 2015.

\section{Authors' Contact Information:}

Herwig Czech, M.A., Ph.D.

Medical University of Vienna

Department of Ethics, Collections, and History of

Medicine (Josephinum)

Contact: herwig.czech@meduniwien.ac.at

\section{Christiane Druml, LL.D.}

Medical University of Vienna

Department of Ethics, Collections, and History of

Medicine (Josephinum)

Contact: christiane.druml@meduniwien.ac.at

Wolfgang J. Weniger, M.D.

Medical University of Vienna

Division of Anatomy

Contact: wolfgang.weninger@meduniwien.ac.at 


\section{Markus Müller, M.D.}

Rector of the Medical University of Vienna

Contact: markus.mueller@meduniwien.ac.at

\section{Licensing}

These authors have chosen to license this content under a Creative Commons Attribution, NonCommercial, NoDerivatives 4.0 International License.

\section{(c) (i) $(\Theta)$}

BY NC ND

Authorization for publication of images from Pernkopf's atlas has been granted for use in this article only. The atlas images must remain within the context of this article for open-access, scholarship and educational use. The atlas images in this article may not be removed from this article, nor reproduced, nor distributed, outside of the context of this article, for scholarly, education or commercial purposes, without the expressed permission of the Josephinum.

\section{Conflict of Interest Statement}

The Journal of Biocommunication Management Board and Editors believe that transparency in academic research is essential. Our $J B C$ authors are now required to disclose any possible conflict of interest when submitting a manuscript. In accordance with the Journal of Biocommunication's editorial policy, no potential conflict of interest has been reported or declared by the authors. 